\title{
GLP-1 mediated diuresis and natriuresis are blunted in heart failure and restored by selective afferent renal denervation
}

\author{
Kenichi Katsurada', Shyam S. Nandi ${ }^{1}$, Hong Zheng ${ }^{2}$, Xuefei Liư ${ }^{2}$, Neeru M. Sharma ${ }^{1}$ and Kaushik P. Patel ${ }^{*}$
}

\begin{abstract}
Background: Glucagon-like peptide-1 (GLP-1) induces diuresis and natriuresis. Previously we have shown that GLP-1 activates afferent renal nerve to increase efferent renal sympathetic nerve activity that negates the diuresis and natriuresis as a negative feedback mechanism in normal rats. However, renal effects of GLP-1 in heart failure (HF) has not been elucidated. The present study was designed to assess GLP-1-induced diuresis and natriuresis in rats with HF and its interactions with renal nerve activity.

Methods: HF was induced in rats by coronary artery ligation. The direct recording of afferent renal nerve activity (ARNA) with intrapelvic injection of GLP-1 and total renal sympathetic nerve activity (RSNA) with intravenous infusion of GLP-1 were performed. GLP-1 receptor expression in renal pelvis, densely innervated by afferent renal nerve, was assessed by real-time PCR and western blot analysis. In separate group of rats after coronary artery ligation selective afferent renal denervation (A-RDN) was performed by periaxonal application of capsaicin, then intravenous infusion of GLP-1-induced diuresis and natriuresis were evaluated.
\end{abstract}

Results: In HF, compared to sham-operated control; (1) response of increase in ARNA to intrapelvic injection of GLP-1 was enhanced (3.7 \pm 0.4 vs. $2.0 \pm 0.4 \mu \mathrm{V}$ s), (2) GLP-1 receptor expression was increased in renal pelvis, (3) response of increase in RSNA to intravenous infusion of GLP-1 was enhanced (132 $\pm 30 \%$ vs. $70 \pm 16 \%$ of the baseline level), and (4) diuretic and natriuretic responses to intravenous infusion of GLP-1 were blunted (urine flow $53.4 \pm 4.3 \mathrm{vs.}$ $78.6 \pm 4.4 \mu \mathrm{l} / \mathrm{min} / \mathrm{gkw}$, sodium excretion $7.4 \pm 0.8 \mathrm{vs}$. $10.9 \pm 1.0 \mu \mathrm{Eq} / \mathrm{min} / \mathrm{gkw}$ ). A-RDN induced significant increases in diuretic and natriuretic responses to GLP-1 in HF (urine flow $96.0 \pm 1.9 \mathrm{vs} .53 .4 \pm 4.3 \mu \mathrm{l} / \mathrm{min} / \mathrm{gkw}$, sodium excretion $13.6 \pm 1.4$ vs. $7.4 \pm 0.8 \mu \mathrm{Eq} / \mathrm{min} / \mathrm{gkw}$ ).

Conclusions: The excessive activation of neural circuitry involving afferent and efferent renal nerves suppresses diuretic and natriuretic responses to GLP-1 in HF. These pathophysiological responses to GLP-1 might be involved in the interaction between incretin-based medicines and established HF condition. RDN restores diuretic and natriuretic effects of GLP-1 and thus has potential beneficial therapeutic implication for diabetic HF patients.

Keywords: Glucagon-like peptide-1, Renal afferent, Sympathetic nerve activity, Sodium and water homeostasis, Heart failure

\footnotetext{
*Correspondence: kpatel@unmc.edu

${ }^{1}$ Department of Cellular and Integrative Physiology, University

of Nebraska Medical Center, 985850 Nebraska Medical Center, Omaha, NE 68198-5850, USA

Full list of author information is available at the end of the article
}

\section{Background}

Glucagon-like peptide-1 (GLP-1), incretin hormone, is secreted from epithelial cells in small intestine after meal ingestion and acts on the pancreas to promote insulin secretion. GLP-1 also suppresses appetite and increases energy expenditure to regulate glucose and

(c) The Author(s) 2020. This article is licensed under a Creative Commons Attribution 4.0 International License, which permits use, sharing, adaptation, distribution and reproduction in any medium or format, as long as you give appropriate credit to the original author(s) and the source, provide a link to the Creative Commons licence, and indicate if changes were made. The images or other third party material in this article are included in the article's Creative Commons licence, unless indicated otherwise in a credit line to the material. If material is not included in the article's Creative Commons licence and your intended use is not permitted by statutory regulation or exceeds the permitted use, you will need to obtain permission directly from the copyright holder. To view a copy of this licence, visit http://creativeco mmons.org/licenses/by/4.0/. The Creative Commons Public Domain Dedication waiver (http://creativecommons.org/publicdomain/ zero/1.0/) applies to the data made available in this article, unless otherwise stated in a credit line to the data. 
energy metabolism [1, 2]. Based on these properties, GLP-1 related medicines are now widely used as one of the major strategies for treatment of type-2 diabetes and obesity. To date, cardiovascular outcome studies show that GLP-1 receptor (GLP-1R) agonists reduce atherosclerotic events including myocardial infarction and stroke, and also prevent progression of chronic kidney disease in type-2 diabetic patients [3-5]. On the other hand, GLP-1R agonists don't affect the risk of heart failure (HF). Furthermore, the effects of GLP-1 on HF, especially established/symptomatic HF, are poorly understood and has been a subject of active debate [6-9].

GLP-1Rs are widely expressed in the whole body including the kidney $[1,10-15]$ and GLP-1 has diuretic and natriuretic effects in humans and animal models of hypertension, diabetes and obesity $[10,12,13,16]$. As underlying mechanisms, it has been reported that GLP-1 causes renal vasodilatation, increases renal blood flow, increases glomerular filtration rate, inhibits the $\mathrm{Na}^{+} / \mathrm{H}^{+}$ exchanger 3 in proximal tubule and decreases sodium, bicarbonate and water reabsorption [12, 14]. In mice GLP-1R is expressed in the atrium of the heart and GLP$1 \mathrm{R}$ agonist promotes the secretion of atrial natriuretic peptide [17], which consequently causes diuresis and natriuresis. In addition to these direct effects on the kidney and the heart, it is likely that GLP-1 regulates diuresis and natriuresis via neural mechanisms as well. GLP-1 has been reported to act on neural pathways by acting on areas of the brain with a weak blood brain barrier [18-20] and vagal afferent [21-23]. Recently we have shown that GLP-1 activates afferent renal nerves to increase efferent renal sympathetic nerve activity that negates the diuresis and natriuresis produced by GLP-1 in normal rats [24]. However, the renal effects of GLP-1 in pathological conditions such as HF have not been elucidated to date.

The present study was conducted to assess the effect of GLP-1 on both the sensory afferent renal nerves and motor efferent renal sympathetic nerves in rats with HF, induced by coronary artery ligation and its relevance to diuresis and natriuresis, and hemodynamic changes in response to intravenous infusion of GLP-1. To address the relative contributions of afferent vs. efferent renal nerves to regulation of GLP-1 mediated diuresis and natriuresis in $\mathrm{HF}$, either total renal denervation with surgical cutting of the renal nerves or a selective afferent renal denervation with periaxonal application of capsaicin were performed as demonstrated previously [24-26].

\section{Methods}

\section{Animals}

Male Sprague-Dawley rats weighing 220 to 250 g were purchased from Sasco Breeding Laboratories (Omaha, $\mathrm{NE}$ ). Animals were housed with a 12-h light-dark cycle at ambient $22{ }^{\circ} \mathrm{C} 30-40 \%$ relative humidity. Laboratory chow and tap water were available ad libitum.

\section{Induction of heart failure}

Rats were randomly assigned to either a Sham-operated control group or a HF group. HF was produced by left coronary artery ligation, as previously described with slight modification [27-30]. The rats were anesthetized with 3 to $4 \%$ isoflurane inhalation in an anesthesia chamber, and orally intubated to facilitate artificial ventilation. The tidal volume was adjusted for each animal to provide normal chest expansion. During the procedure, 2 to $2.5 \%$ isoflurane was used. Adequacy of the anesthesia was confirmed by the lack of the response to paw pinches during the surgical procedure. A left thoracotomy was performed at the 4th intercostal space. This allows visualization of the left coronary artery without having to lift the heart. In the HF group, the left coronary artery was ligated 1-2 mm below its origin from the aorta. The sham rats underwent thoracotomy and manipulation of the heart, but the coronary artery was not ligated. After these maneuvers, a silastic chest tube was inserted between the 5 and 6th ribs and the thorax was closed. The air within the thorax was aspirated by means of the chest tube while hyperinflating the lungs. The chest tube was then removed, and the rat was allowed to recover from the anesthesia and the endotracheal tube was removed. The rats were treated with analgesics (buprenorphine, $0.1 \mathrm{mg} / \mathrm{kg}$, s.c.) for 3 postoperative days. The severity of HF was determined by both cardiac functional and histological assessment. A week before the terminal experiments, echocardiograms (Vevo 3100, $15-\mathrm{MHz}$ probe; Visual Sonics, Inc., Toronto, Canada) were performed. Under anesthesia with 2 to $2.5 \%$ isoflurane inhalation, rats were placed on a heated stage that recorded electrocardiogram, respiratory rate and body temperature. Adequacy of the anesthesia was confirmed by the lack of the response to paw pinches and monitoring heart rate during the procedure. Left ventricular end-diastolic dimension (LVEDD), left ventricular end-systolic dimension (LVESD), fractional shortening (FS), ejection fraction (EF), left ventricular end-diastolic volume (LVEDV), left ventricular end-systolic volume (LVESV), stroke volume (SV) and cardiac output (CO) were analyzed by using Visual Sonics software. At the time of the terminal experiments, hemodynamic measurement was performed by using a Mikro-Tip catheter (SPR-407, Millar Instruments, Houston, TX) to obtain left ventricular end-diastolic pressure (LVEDP), left ventricular end-systolic pressure (LVESP), heart rate, maximal slope of systolic pressure increment $(+\mathrm{dP} / \mathrm{dt})$ and diastolic pressure decrement $(-\mathrm{dP} / \mathrm{dt})$. Further, to anatomically assess the extent of HF, infarct size of the left ventricle (LV) was 
calculated. The heart was dissected and the atria and right ventricle were removed. The LV was longitudinally cut and laid flat. A digital image of the LV was captured by a digital camera. Infarct size was measured by dividing the size of the infarcted area by the total size of the LV using ImageJ software (National Institutes of Health). Rats with both LVEDP > $15 \mathrm{mmHg}$ and infarct size > 30\% were considered to be in HF. All experiments were performed 5-6 weeks after coronary ligation surgery, unless otherwise specifically noted.

\section{Intrapelvic injection of GLP-1 with direct recording of afferent renal nerve activity (ARNA)}

Rats were anesthetized with urethane $(0.75 \mathrm{~g} / \mathrm{kg}$, i.p. $)$ and $\alpha$-chloralose $(70 \mathrm{mg} / \mathrm{kg}$, i.p.). This anesthetic is specifically chosen to minimize the effects of anesthesia on central pathways involved in autonomic regulation of the cardiovascular system. Under this anesthesia a lot of the autonomic reflex functions are studied and are operational $[24,26,29,31-33]$ and therefore being used in current study examining effects of GLP-1 on neural circuitry of renal nerve activity involved in central nervous system. Body temperature was controlled at $36-38{ }^{\circ} \mathrm{C}$ by a stage heater. Tracheal intubation was performed to make the rats breathe independently. The PE-50 polyethylene tubing was insert into the right femoral artery and connected to a pressure transducer. PowerLab software (8SP, AD Instruments, Colorado Spring, CO) was used to record mean arterial pressure (MAP) and heart rate (HR), simultaneously. The right femoral vein was cannulated with PE-50 tubing for intravenous supplemental anesthesia. Adequacy of the anesthesia was confirmed by the lack of the response to paw pinches during the surgical procedure. The direct recording of ARNA with intrapelvic injections was performed as described previously $[24,26,34,35]$. Briefly, the left kidney was exposed through a retroperitoneal flank incision. The renal pelvis was cannulated with a $32 \mathrm{G}$ triple-lumen catheter (ReCathCo, Allison Park, PA) via the ureter for intrapelvic perfusion and withdrawal of infusate and monitoring of pelvic pressure. A renal nerve branch located at the renal hilus was isolated and gently put on a bipolar silver electrode. The nerve-electrode junction was electrically isolated from surrounding tissue with gel (Wacker, St. Louis, MO). Grass amplifier was used to amplify the electrical signal with high- and low-frequency cutoffs of $1000 \mathrm{~Hz}$ and $100 \mathrm{~Hz}$, respectively. The PowerLab system was used to record the rectified output (resister capacitor filtered, time constant, $0.5 \mathrm{~s}$ ) and integrate the raw nerve discharge. First, the total basal renal nerve discharge was recorded. Then, the afferent nerve discharge and background noise were obtained after sectioning proximal end of the nerve to eliminate efferent nerve signal.
Finally, the background noise was recorded after sectioning the distal end of the nerve. The value of ARNA was obtained by subtracting the background noise from the integrated signal. For description of ARNA response to intrapelvic injection of GLP-1 ( $3 \mu \mathrm{M}$ in saline, Enzo Life science, Farmingdale, NY), ARNA was expressed as a percent changes from the baseline value and also normalized to maximal ARNA induced by intrapelvic injection of capsaicin $(100 \mu \mathrm{M}$ in $5 \%$ ethanol and $95 \%$ saline, Sigma, Saint Louis, MO) thus expressed as a percent of ARNAmax as shown previously [24,26,34]. At the end of the experiment, rats were euthanized by an overdose of pentobarbital $(150 \mathrm{mg} / \mathrm{kg}$, i.p.).

\section{Real-time quantitative reverse-transcription polymerase chain reaction (qRT-PCR) for GLP-1R in the renal pelvis}

The kidneys of rats were removed and frozen on dry ice and then stored at $-80{ }^{\circ} \mathrm{C}$. Total RNA from pelvis in the kidney was isolated using TRIzol (Invitrogen, Madison, WI) and the purity and concentration of total RNA was quantified using Nanodrop 2000C (Thermo Fisher Scientific, Waltham, MA). Pure quality (A260/A280 > 1.8-2.0) RNA was used for cDNA synthesis and qPCR assay. First-strand cDNA synthesis was completed from $1 \mu \mathrm{g}$ of RNA using the iScript cDNA Synthesis Kit (catalog number: 170-8841, Bio-Rad Laboratories, Hercules, CA). The qPCR assay was performed using $2 \times$ iTaq Universal SYBR Green Supermix (catalog number: 1725121, BioRad Laboratories, Hercules, CA) according to the BioRad manufacturer's instructions. The qPCR mixture was amplified with the protocol $95{ }^{\circ} \mathrm{C}$ for 5 min pre-denaturation and then 35 cycles of $95^{\circ} \mathrm{C}$ for $20 \mathrm{~s}, 57^{\circ} \mathrm{C}$ for $30 \mathrm{~s}$, and $72{ }^{\circ} \mathrm{C}$ for $45 \mathrm{~s}$ in a Bio-Rad CFX qPCR System. A $10 \mu \mathrm{l}$ qCR reaction was amplified in duplicate wells for each sample $4.5 \mu \mathrm{l}$ of cDNA mixture (100 ng cDNA template + rest nuclease-free water) with $5 \mu$ iTaq Universal SYBR Green Supermix, and $0.5 \mu \mathrm{l}$ forward and reverse primer mixtures $(10 \mathrm{pm})$. Bio-Rad CFX Manager 3.0 software was used for the relative quantification of mRNA expression in fold change $\left(2^{-\Delta \Delta \mathrm{Ct}}\right)$ using 18 sRNA as a reference control. The details of primer sequences used are: Rat GLP-1R forward; 5'-CTTTGATGACTACGCCTG CT- $3^{\prime}$, reverse; $5^{\prime}$-CTTGGACTCTTCGCACTCC- $3^{\prime}$ and, rat $18 \mathrm{~S}$ ribosomal RNA: forward; $5^{\prime}$-TGTGATGCCCTT AGATGTCC- ${ }^{\prime}$ reverse; 5'-TTATGACCCGCACTTACT GG-3'.

\section{Western blot analysis for protein expression of GLP-1R in the renal pelvis}

The kidneys of rats were removed, frozen on dry ice and then stored at $-80{ }^{\circ} \mathrm{C}$. The protein extracts from pelvis in the kidney were used for western blot analysis as described previously [24, 26]. Samples were processed 
for protein isolation using RIPA buffer (Boston Bioproduct, Ashland, MA) with protease inhibitors cocktail (Cell signaling technology, Danvers, MA), quantified by Pierce BCA Protein Assay Kit (Thermo Fisher Scientific, Waltham, MA) and $40 \mu \mathrm{g}$ of proteins were boiled with $4 \times$ denaturing Laemmli Sample Buffer (Bio-Rad Laboratories, Hercules, CA) and loaded on 7.5\% SDSPAGE gel. Post-electrophoresis, gels were transferred onto polyvinylidene difluoride membranes, which were then blocked with $5 \%$ non-fat dried milk in tris-buffered saline with tween 20 (TBST) for $1 \mathrm{~h}$ at room temperature. The membranes were incubated with primary antibody (mouse anti-GLP-1R, sc-390774, Santa Cruz Biotechnology, Santa Cruz, CA, 1:1000 and rabbit anti-GAPDH, sc-25778, Santa Cruz Biotechnology, Santa Cruz, CA, 1:1000) in TBST overnight at $4{ }^{\circ} \mathrm{C}$. After washing, the membranes were incubated with secondary antibodies conjugated with horseradish peroxidase diluted at 1:5000 in TBST for $1 \mathrm{~h}$ at room temperature. Signals for protein bands were developed with Super Signal West Femto Chemiluminescent kit (Thermo Fisher Scientific, Waltham, MA) and detected by a Molecular Imager ChemiDoc XRS imaging system (Bio-Rad Laboratories, Hercules, CA). The protein bands were quantified by Image Lab software version 6 (Bio-Rad Laboratories, Hercules, CA). The protein levels of GLP-1R were expressed as the intensity of its band signal normalized to the intensity of the GAPDH signal.

\section{Intravenous infusion of GLP-1 with direct recording of renal sympathetic nerve activity (RSNA)}

Rats were anesthetized with urethane $(0.75 \mathrm{~g} / \mathrm{kg}$, i.p. $)$ and $\alpha$-chloralose (70 mg/kg, i.p.). This anesthetic is chosen due to specific reasons described in the direct recording of ARNA. Adequacy of the anesthesia was confirmed by the lack of the response to paw pinches during the surgical procedure. The PE-50 polyethylene tubing was inserted into the right femoral artery and connected to a pressure transducer. PowerLab software (8SP, AD Instruments, Colorado Spring, CO) was used to record MAP and HR, simultaneously. Another PE-50 tubing was inserted into the right femoral vein to infuse isotonic saline $(0.9 \% \mathrm{NaCl})$ at a rate of $50 \mu \mathrm{l} / \mathrm{min}$ throughout the experiment, except the period of GLP-1 infusion $(1 \mu \mathrm{g} /$ $\mathrm{kg} / \mathrm{min}$ ) for $30 \mathrm{~min}$. RSNA recording was performed as described in ARNA recording without cutting the renal nerve. The background noise was recorded after cutting both the proximal and the distal end of the nerve. The peak change in RSNA response to intravenous infusion of GLP-1 was expressed as a percent of the baseline level as shown previously [24]. At the end of the experiment, rats were euthanized by an overdose of pentobarbital (150 mg/kg, i.p.).

\section{Acute total renal denervation (T-RDN)}

Acute T-RDN was performed as described previously $[30,31,36]$. Briefly, the hilus of the left kidney was exposed retroperitoneally and all visible renal nerves were cut by using microsurgical scissors. Then $95 \%$ ethanol was painted around the renal artery and vein by using cotton swabs to ensure ablation of remaining nerve fibers. This technique has previously been validated as the efficacy in reducing renal norepinephrine content to under $5 \%$ of the normal levels $[30,31,36]$.

\section{Chronic selective afferent renal denervation (A-RDN)}

Four weeks after coronary artery ligation surgery, afferent renal denervation was performed as described previously [24-26]. Briefly, rats were anesthetized with 2 to $2.5 \%$ isoflurane inhalation. Adequacy of the anesthesia was confirmed by the lack of the response to paw pinches during the surgical procedure. The kidneys were exposed through abdominal midline incision. A small piece of filter paper soaked in a capsaicin solution $(33 \mathrm{mM}$ in $10 \%$ ethanol, $10 \%$ tween 80 and $80 \%$ saline, Sigma, Saint Louis, $\mathrm{MO})$ was wrapped around the vessels for $10 \mathrm{~min}$. During the procedure, parafilm was placed under the vessels to prevent capsaicin exposure to any other adjacent visceral tissues. After $10 \mathrm{~min}$ of capsaicin exposure, the filter paper and parafilm were removed. The same procedure was conducted on the contralateral side. The rats were treated with analgesics (buprenorphine, $0.1 \mathrm{mg} / \mathrm{kg}$, s.c.) for 3 postoperative days. The acute terminal experiments were performed at between 1 and 2 weeks after A-RDN (5-6 weeks after the coronary artery ligation). To validate the effectiveness of A-RDN, protein levels of calcitonin gene-related peptide (CGRP), which is the dominant neurotransmitter for afferent renal nerves [37, 38], and tyrosine hydroxylase (TH), a marker for efferent sympathetic fibers in the renal pelvis were quantified. The western blot analysis for CGRP (rabbit anti-CGRP, BMLCA1134, Enzo Life Sciences, Farmingdale, NY, 1:2000) and TH (mouse anti-TH, sc-25269, Santa Cruz Biotechnology, Santa Cruz, CA, 1:1000) on protein extracts from renal pelvis were performed as described above with $12 \%$ SDS-PAGE gel to quantify the extent of ablation of afferent sensory nerves and determine if there was any damage to the efferent adrenergic innervation due to selective A-RDN in the pelvic wall of the kidney. 


\section{Measurement of hemodynamic, diuretic and natriuretic responses to GLP-1}

Rats were assigned randomly to one of six groups: Sham, Sham + T-RDN, Sham + A-RDN, HF, HF+T-RDN, $\mathrm{HF}+\mathrm{A}-\mathrm{RDN}$ with $\mathrm{n}=6-10$ /group. Rats were anesthetized with Inactin $(100 \mathrm{mg} / \mathrm{kg}$, i.p.). This anesthetic is specifically chosen to minimize the effects on changes in blood pressure and thus provide an ideal perfusion pressure to the kidneys to perform renal function study. Under this anesthesia a lot of renal function studies [24, $28,30,31,39,40]$ are operational and therefore being used in current study examining effects of GLP-1 on renal hemodynamics and excretion. Body temperature was controlled at $36-38{ }^{\circ} \mathrm{C}$ by a stage heater. Tracheal intubation was performed to make the rats breathe independently. The PE-50 tubing was inserted into the right femoral artery and connected to a pressure transducer for monitoring of MAP and HR. Another PE-50 tubing was inserted into the right femoral vein for isotonic saline infusion $(50 \mu \mathrm{l} / \mathrm{min})$ to create steady state condition for urine production and for GLP-1 infusion $(1 \mu \mathrm{g} / \mathrm{kg} / \mathrm{min})$. For collecting urine, both ureters were approached retroperitoneally and cannulated with PE-10 tubing individually. The surgical procedures were completed within an hour. Adequacy of the anesthesia was confirmed by the lack of the response to paw pinches during the surgical procedure. Two urine collections (15 min each) were obtained over $30 \mathrm{~min}$ baseline period before starting GLP-1 infusion $(1 \mu \mathrm{g} / \mathrm{kg} / \mathrm{min}$, i.v.). During GLP-1 infusion, urine was collected at 10, 20 and $30 \mathrm{~min}$. After the termination of GLP-1 infusion, urine was collected at 40, 50 and $60 \mathrm{~min}$. Urine volume was measured by subtracting the weight of tube before collecting urine from the weight of tube containing urine. A selective ion electrode (Beckman ion analyzer, Brea, CA) was used to measure sodium concentration of the urine samples. The creatinine levels in the urine and blood samples collected in citrate-containing tube were measured by using commercially available assay kits (ab65340, Abcam, Cambridge, MA). Creatinine clearance $(\mathrm{CrCl})$ was then calculated. At the end of the experiments, rats were euthanized by an overdose of pentobarbital $(150 \mathrm{mg} / \mathrm{kg}$, i.p.) and then heart and kidneys were harvested.

\section{Statistical analysis}

All data are expressed as mean \pm SEM. Data were tested for significance using a Student's $t$-test for two normally distributed groups. Data from three groups or more were assessed by an ordinary one-way ANOVA test followed by Bonferroni post hoc analysis. Data from experiments with two or more variables were assessed by two-way ANOVA followed by Bonferroni post hoc analysis. $P$-values $<0.05$ were indicative of statistical significance. All
Table 1 Baseline cardiac characteristics of Sham and HF rats

\begin{tabular}{|c|c|c|}
\hline & $\begin{array}{l}\text { Sham } \\
(n=10)\end{array}$ & $\begin{array}{l}\mathrm{HF} \\
(n=10)\end{array}$ \\
\hline Body weight: BW (g) & $356 \pm 6$ & $370 \pm 7$ \\
\hline Heart weight: HW (g) & $1.2 \pm 0.1$ & $1.6 \pm 0.1^{*}$ \\
\hline HW/BW* 1000 & $3.2 \pm 0.1$ & $4.3 \pm 0.2^{*}$ \\
\hline Infarct size (\% of endocardial LV) & 0 & $39 \pm 2^{*}$ \\
\hline LVEDP $(\mathrm{mmHg})$ & $3 \pm 1$ & $21 \pm 3^{*}$ \\
\hline LVESP $(m m H g)$ & $119 \pm 4$ & $106 \pm 3$ \\
\hline Heart rate (bpm) & $350 \pm 14$ & $361 \pm 14$ \\
\hline$+\mathrm{dP} / \mathrm{dt}(\mathrm{mmHg} / \mathrm{s})$ & $7161 \pm 584$ & $4783 \pm 281^{*}$ \\
\hline$-\mathrm{dP} / \mathrm{dt}(\mathrm{mmHg} / \mathrm{s})$ & $-6878 \pm 552$ & $-3745 \pm 172^{*}$ \\
\hline $\operatorname{LVEDD~}(\mathrm{mm})$ & $8.0 \pm 0.2$ & $10.4 \pm 0.2^{*}$ \\
\hline $\operatorname{LVESD}(\mathrm{mm})$ & $4.8 \pm 0.1$ & $8.5 \pm 0.2^{*}$ \\
\hline Fractional shortening (\%) & $39 \pm 1$ & $18 \pm 1^{*}$ \\
\hline Ejection fraction (\%) & $64 \pm 1$ & $33 \pm 1^{*}$ \\
\hline LVEDV $(\mu \mathrm{l})$ & $428 \pm 27$ & $653 \pm 45^{*}$ \\
\hline $\operatorname{LVESV}(\mu \mathrm{l})$ & $151 \pm 14$ & $443 \pm 39^{*}$ \\
\hline Stroke volume $(\mu \mathrm{l})$ & $277 \pm 14$ & $209 \pm 10^{*}$ \\
\hline Cardiac output ( $\mu \mathrm{l} / \mathrm{min})$ & $105 \pm 2$ & $66 \pm 3^{*}$ \\
\hline
\end{tabular}

Values are mean $\pm S E M ; n=10$ for each group of rats. LVEDP, left ventricular end-diastolic pressure

LVESP left ventricular end-systolic pressure, $+d P / d t$ maximal slope of systolic pressure increment. $-d P / d t$ maximal slope of diastolic pressure decrement, LVEDD left ventricular end-diastolic dimension, LVESD left ventricular endsystolic dimension, LVEDV left ventricular end-diastolic volume, LVESD left ventricular end-systolic volume

*P $<0.05$ compared to Sham

statistical analysis was performed using GraphPad Prism 7.0 .

\section{Results \\ Cardiac characteristics of the HF Model}

The baseline cardiac characteristics of Sham and HF rats (5-6 weeks after coronary artery ligation) used in this study are summarized in Table 1 . The infarcted area in HF group was approximately $40 \%$ of the endocardial surface of the left ventricle. Sham rats had no observable damage to the myocardium. LVEDP was significantly increased in HF group compared to Sham group. The $+\mathrm{dP} / \mathrm{dt}$ and $-\mathrm{dP} / \mathrm{dt}$ were significantly decreased in HF group compared with Sham group, indicating decreased contractility and relaxation of the left ventricle in HF group. LVEDD, LVESD, LVEDV and LVESV were significantly increased in HF group compared to Sham group. FS, EF, SV and CO were greatly reduced in HF group compared to Sham group. The cardiac characteristics observed in this study are consistent with previous reports using this model of HF [41-43]. Additionally, substantial number of previous studies [44-51] demonstrated that natriuretic peptide 
levels in both the heart and the serum are significantly increased in rats with HF induced by coronary artery ligation used in the current study. Taken together, the > $30 \%$ infarct size, increased LVEDP, LVEDD, LVESD, LVEDV and LVESV and decreased $\mathrm{dP} / \mathrm{dt}, \mathrm{FS}, \mathrm{EF}, \mathrm{SV}$ and $\mathrm{CO}$ all indicate that rats in HF group were experiencing cardiac dysfunction.

\section{Intrapelvic injection of GLP-1 increases ARNA}

Direct recordings of ARNA responses to intrapelvic injection of GLP-1 and capsaicin from Sham and HF rats are shown in Fig. 1. The basal total RSNA was significantly higher in HF rats compared to Sham rats $(4.49 \pm 0.52$ vs. $2.23 \pm 0.36 \mu \mathrm{V}$ s, $P<0.05$, Fig. 1a, b). The basal ARNA after sectioning the proximal end of the renal nerve was higher in HF rats $(1.44 \pm 0.16$ vs. $0.76 \pm 0.05 \mu \mathrm{V} \mathrm{s}$, $P<0.05$, Fig. 1c, d), consistent with our previous report [25]. Intrapelvic injection of GLP-1 increased ipsilateral ARNA in both Sham and HF rats (Fig. 1c). The peak response to intrapelvic GLP-1 was higher in HF rats $(3.68 \pm 0.38$ vs. $1.97 \pm 0.39 \mu \mathrm{V}$ s, $\mathrm{P}<0.05,66.0 \pm 3.0$ vs $43.9 \pm 4.6 \%$ of ARNAmax, $P<0.05$, Fig. 1 e, $f$ ). The peak response to intrapelvic capsaicin to elicit maximal activation was not statistically different between Sham and HF rats $(4.26 \pm 0.73$ vs. $5.92 \pm 0.57 \mu \mathrm{V} \mathrm{s}, P>0.05$, Fig. $1 \mathrm{c}, \mathrm{g})$. These results demonstrated that not only the resting levels but also the GLP-1-induced activation levels of ARNA were greater in HF compared to Sham.

\section{GLP-1R expression in the renal pelvis}

Real-time qRT-PCR and western blot analysis revealed that there were significant increases in both mRNA (Fig. 2a) and protein (Fig. 2b) levels of GLP-1R in the renal pelvis of rats with HF compared to Sham.

Intravenous infusion of GLP-1 increases RSNA, MAP and HR Direct recordings of RSNA, MAP and HR responses to intravenous infusion of GLP-1 from Sham and HF rat are shown in Fig. 3. Intravenous infusion of GLP-1 increased RSNA, MAP and HR in both Sham and HF rats. The increase in RSNA response to intravenous infusion of GLP-1 was higher in HF rats $(132.1 \pm 29.2 \%$ vs. $69.8 \pm 16.1 \%$ of basal value, $P<0.05$, Fig. $3 \mathrm{~b})$. The increases in MAP and HR responses to intravenous infusion of GLP-1 were not significantly different between Sham and HF rats (Fig. 3b). These results demonstrated that not only the resting levels but also the GLP-1-induced activation levels of total RSNA was greater in HF compared to Sham.

\section{Intravenous infusion of GLP-1 induces diuresis and natriuresis}

Intravenous infusion of GLP-1 increased urine flow and sodium excretion in both Sham and HF rats. Diuretic and natriuretic responses to GLP-1 were blunted in HF rats (urine flow at $20 \mathrm{~min} 53.4 \pm 4.3 \mathrm{vs} .78 .6 \pm 4.4 \mu \mathrm{l} / \mathrm{min} /$ gkw, sodium excretion at $20 \mathrm{~min} 7.4 \pm 0.8$ vs. $10.9 \pm 1.0$ $\mu \mathrm{Eq} / \mathrm{min} / \mathrm{gkw}, P<0.01, \mathrm{n}=10$, Fig. $4 \mathrm{a}, \mathrm{b})$. Baseline levels of cumulative urine flow and sodium excretion were decreased in HF rats $(98.5 \pm 12.6$ vs. $191.1 \pm 36.4 \mu \mathrm{l} /$ gkw and $12.3 \pm 1.1$ vs. $26.8 \pm 4.2 \mu \mathrm{Eq} / \mathrm{gkw}$, respectively, $P<0.05, \mathrm{n}=10$, Fig. $4 \mathrm{c}, \mathrm{d})$. Cumulative urine flow and sodium excretion responses to GLP-1 were also decreased in HF rats $(1951 \pm 166$ vs. $2451 \pm 151 \mu \mathrm{l} / \mathrm{gkw}$ and $275 \pm 25$ vs. $351 \pm 21 \mu \mathrm{Eq} / \mathrm{gkw}$ at $60 \mathrm{~min}$, respectively, $P<0.05, \mathrm{n}=10$, Fig. 4c, d).

\section{Acute T-RDN enhances diuretic and natriuretic responses to GLP-1}

Acute T-RDN was performed by surgical sectioning followed by perivascular application of $95 \%$ ethanol on the around the renal artery and vein. The data of urine flow and sodium excretion from left denervated kidneys in Sham + T-RDN and HF + T-RDN groups were compared with that from intact kidneys in Sham and HF groups, respectively. T-RDN increased baseline levels of cumulative urine flow and sodium excretion in Sham + T-RDN group (326.4 \pm 61.5 vs. $191.1 \pm 36.4 \mu \mathrm{l} /$ gkw and $57.0 \pm 13.2$ vs. $26.8 \pm 4.2 \mu \mathrm{Eq} / \mathrm{gkw}$, respectively, $P<0.05, \mathrm{n}=6-10)$ and $\mathrm{HF}+\mathrm{T}-\mathrm{RDN}$ group $(374.6 \pm 134.2$ vs. $98.5 \pm 12.6 \mu \mathrm{l} / \mathrm{gkw}$ and $59.4 \pm 15.7$ vs. $12.3 \pm 1.1$ $\mu \mathrm{Eq} / \mathrm{gkw}, \quad$ respectively, $\quad P<0.05, \quad \mathrm{n}=7-10) . \quad$ T-RDN enhanced diuretic and natriuretic responses to GLP-1 in Sham + T-RDN group (urine flow at $20 \mathrm{~min} 106.5 \pm 16.2$ vs. $78.6 \pm 4.4 \mu \mathrm{l} / \mathrm{min} / \mathrm{gkw}$, sodium excretion at $20 \mathrm{~min}$ $15.4 \pm 3.0$ vs. $10.9 \pm 1.0 \mu \mathrm{Eq} / \mathrm{min} / \mathrm{gkw}, P<0.01, \mathrm{n}=6-10$, Fig. $5 \mathrm{a}, \mathrm{b}$ ) and HF $+\mathrm{T}-\mathrm{RDN}$ group (urine flow at $20 \mathrm{~min}$ $93.0 \pm 12.6$ vs. $53.4 \pm 4.3 \mu \mathrm{l} / \mathrm{min} / \mathrm{gkw}$, sodium excretion

\footnotetext{
(See figure on next page.)

Fig. 1 ARNA response to intrapelvic injection of GLP-1. a Raw tracings of integrated and RSNA from Sham and HF rats. b Summary data for basal RSNA. c Raw tracings of integrated and ARNA from Sham and HF rats. The ARNA was recorded before and after intrapelvic injection of GLP-1 $3 \mu M$ or capsaicin $100 \mu \mathrm{M}$ to determine the peak level of ARNA (ARNAmax). d Summary data for ARNA. e Summary data for peak ARNA responses to GLP-1 expressed as an absolute value. $\mathbf{f}$ Summary data for peak ARNA responses to GLP-1 expressed a percentage of ARNAmax. $\mathbf{g}$ Summary data for peak ARNA responses to capsaicin. $\mathrm{n}=6 .{ }^{*} P<0.05 \mathrm{vs}$. Sham
} 


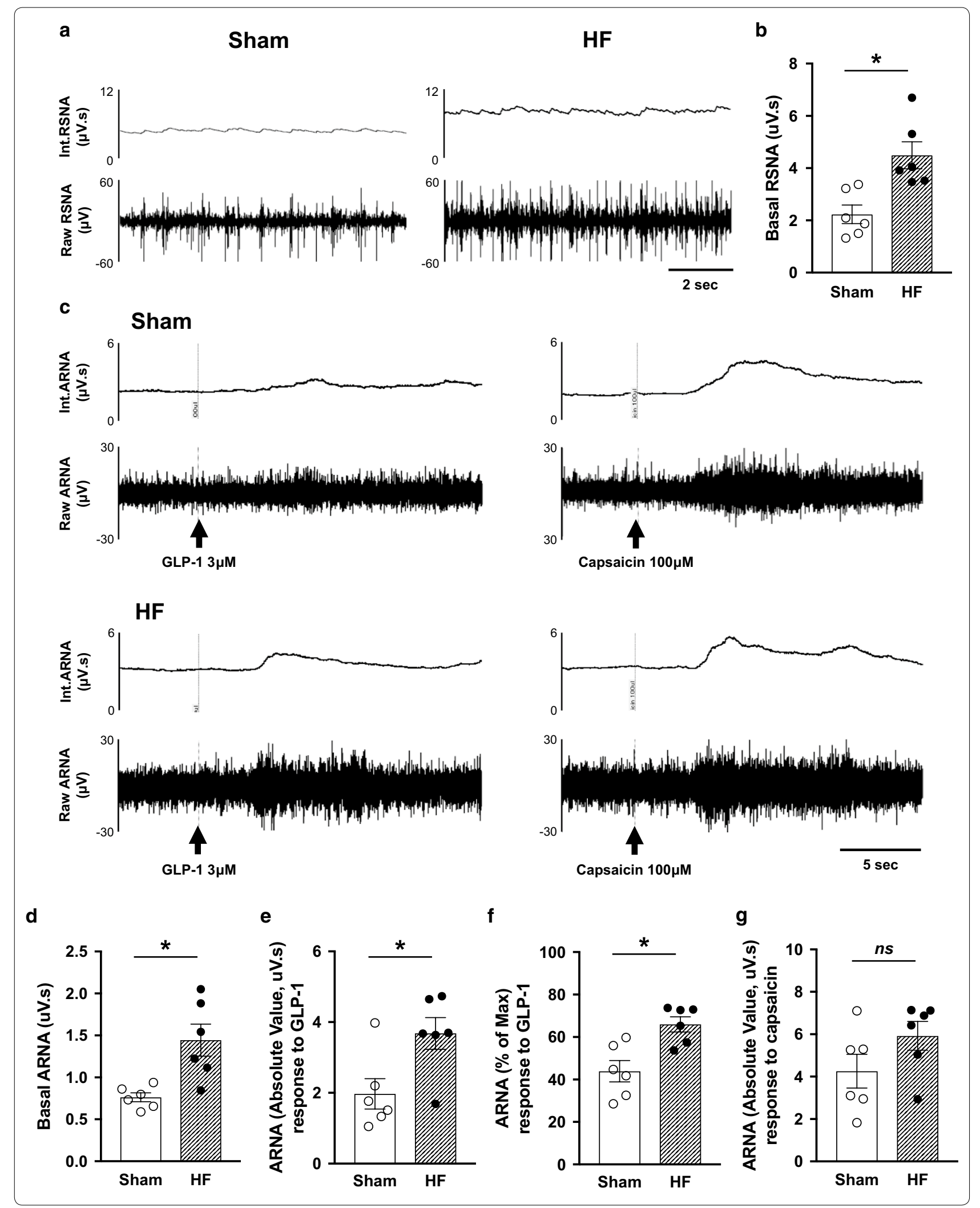


a
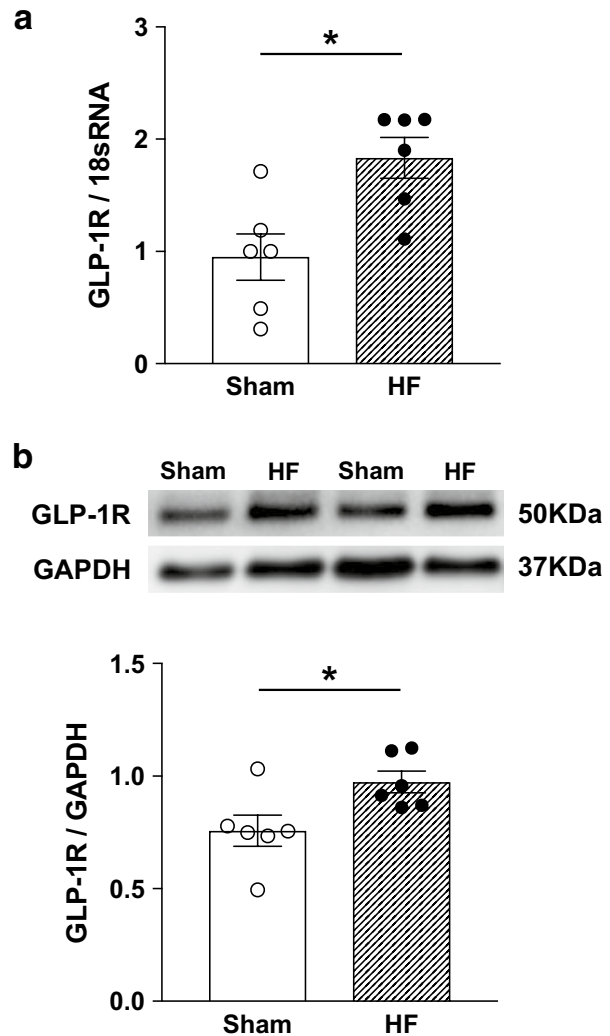

Fig. 2 GLP-1R expression in the renal pelvis. Real-time qRT-PCR (a) and western blot analysis (b) for GLP-1R in the renal pelvis of Sham and HF rats. $n=6 .{ }^{*} P<0.05$ vs. Sham

at $20 \mathrm{~min} 14.2 \pm 1.6$ vs. $7.4 \pm 0.8 \mu \mathrm{Eq} / \mathrm{min} / \mathrm{gkw}, P<0.01$, $\mathrm{n}=7-10$, Fig. 5c, d).

\section{Chronic A-RDN enhances diuretic and natriuretic responses to GLP-1}

A-RDN was performed by bilateral perivascular application of capsaicin on the renal nerves. Either 1 or 2 weeks after A-RDN, there were enhanced diuretic and natriuretic responses to GLP-1 in Sham + A-RDN group (urine flow at $20 \mathrm{~min} 104.2 \pm 9.6$ vs. $78.6 \pm 4.4 \mu \mathrm{l} / \mathrm{min} / \mathrm{gkw}$, sodium excretion at $20 \mathrm{~min} 15.4 \pm 3.0$ vs. $10.9 \pm 1.0 \mu \mathrm{Eq} /$ $\mathrm{min} / \mathrm{gkw}, P<0.01, \mathrm{n}=6-10$, Fig. $5 \mathrm{a}, \mathrm{b})$ and HF $+\mathrm{A}-\mathrm{RDN}$ group (urine flow at $20 \mathrm{~min} 96.0 \pm 1.9$ vs. $53.4 \pm 4.3 \mu \mathrm{l} /$ $\mathrm{min} / \mathrm{gkw}$, sodium excretion at $20 \mathrm{~min} 13.6 \pm 1.4$ vs. $7.4 \pm 0.8 \mu \mathrm{Eq} / \mathrm{min} / \mathrm{gkw}, P<0.01, \mathrm{n}=6-10$, Fig. $5 \mathrm{c}, \mathrm{d})$. The effects of T-RDN on responses of increases in urine flow and sodium excretion to GLP-1 were not significantly different from those observed with A-RDN. Figure 6 shows the protein expression of CGRP and TH in the renal pelvis of rats with or without capsaicin treatment. CGRP was decreased by $62-75 \%$ in rats with capsaicin treatment, while $\mathrm{TH}$ was not different between the rats with and without capsaicin treatment. These results indicate that capsaicin treatment selectively ablated renal afferent innervation but did not affect renal efferent noradrenergic innervation, validating the effectiveness of capsaicin treatment to produce A-RDN.

\section{Either T-RDN or A-RDN attenuates increases in MAP and HR} responses to GLP-1

MAP and HR were significantly increased during intravenous infusion of GLP-1 in both Sham and HF rats. There were no statistical differences in MAP and HR between Sham and HF rats. These changes in MAP and HR to GLP-1 were significantly attenuated by either T-RDN or A-RDN in both Sham and HF rats. These changes in MAP and HR to GLP-1 were not statistically different between the two groups, Sham + T-RDN and Sham + A-RDN (Fig. 7a, b) or HF+T-RDN and $\mathrm{HF}+\mathrm{A}-\mathrm{RDN}$ (Fig. 7c, d). Table 2 shows the changes of $\mathrm{CrCl}$ during intravenous infusion of GLP-1. Baseline $\mathrm{CrCl}$ was lower in $\mathrm{HF}$ than Sham $(817 \pm 101$ vs. $1356 \pm 109 \mu \mathrm{l} / \mathrm{min} / \mathrm{gkw}, P<0.05, \mathrm{n}=5)$. T-RDN increased baseline $\mathrm{CrCl}$ in both Sham + T-RDN $(1893 \pm 137$ vs. $1356 \pm 109 \mu \mathrm{l} / \mathrm{min} / \mathrm{gkw}, P<0.05, \mathrm{n}=5)$ and $\mathrm{HF}+\mathrm{T}-\mathrm{RDN}$ group $(1858 \pm 215$ vs. $817 \pm 101 \mu \mathrm{l} / \mathrm{min} / \mathrm{gkw}, P<0.05$, $n=5)$. Intravenous infusion of GLP-1 significantly increased $\mathrm{CrCl}$ in both Sham + T-RDN $(2978 \pm 213$ vs. $2225 \pm 94 \mu \mathrm{l} / \mathrm{min} / \mathrm{gkw}, P<0.05, \mathrm{n}=5)$ and HF $+\mathrm{T}-\mathrm{RDN}$ group $(2868 \pm 178$ vs. $1725 \pm 108 \mu \mathrm{l} / \mathrm{min} / \mathrm{gkw}, P<0.05$, $\mathrm{n}=5)$. $\mathrm{CrCl}$ response to GLP-1 in HF + T-RDN was comparable to that in Sham + T-RDN.

\section{Discussion}

We have shown that baseline ARNA was elevated in rats with HF. The response of an increase in ARNA to intrapelvic injection of GLP-1 was enhanced in HF. Consistent with these observations GLP-1R expression in the renal pelvis was augmented in HF. The response of an increase in RSNA to intravenous infusion of GLP-1 was also exaggerated in HF. Diuretic and natriuretic responses to GLP-1 were blunted in HF and restored by either T-RDN or A-RDN to the comparable levels with that in Sham. These changes to GLP-1 were not significantly different between T-RDN and A-RDN in both HF and Sham groups. The main findings deduced by the results in this study are as follow: (1) GLP-1 increases RSNA to regulate diuresis and natriuresis in an inhibitory manner, in which the afferent renal nerve activation is potentiated via elevated GLP-1R expression in the renal pelvis of rats with HF. (2) Either T-RDN or A-RDN inhibits the activation of neural circuitry utilizing the renal nerves to enhance the diuretic and natriuretic responses to GLP-1.

We have shown that basal ARNA was higher in HF than Sham consistent with our previous report [26] as 


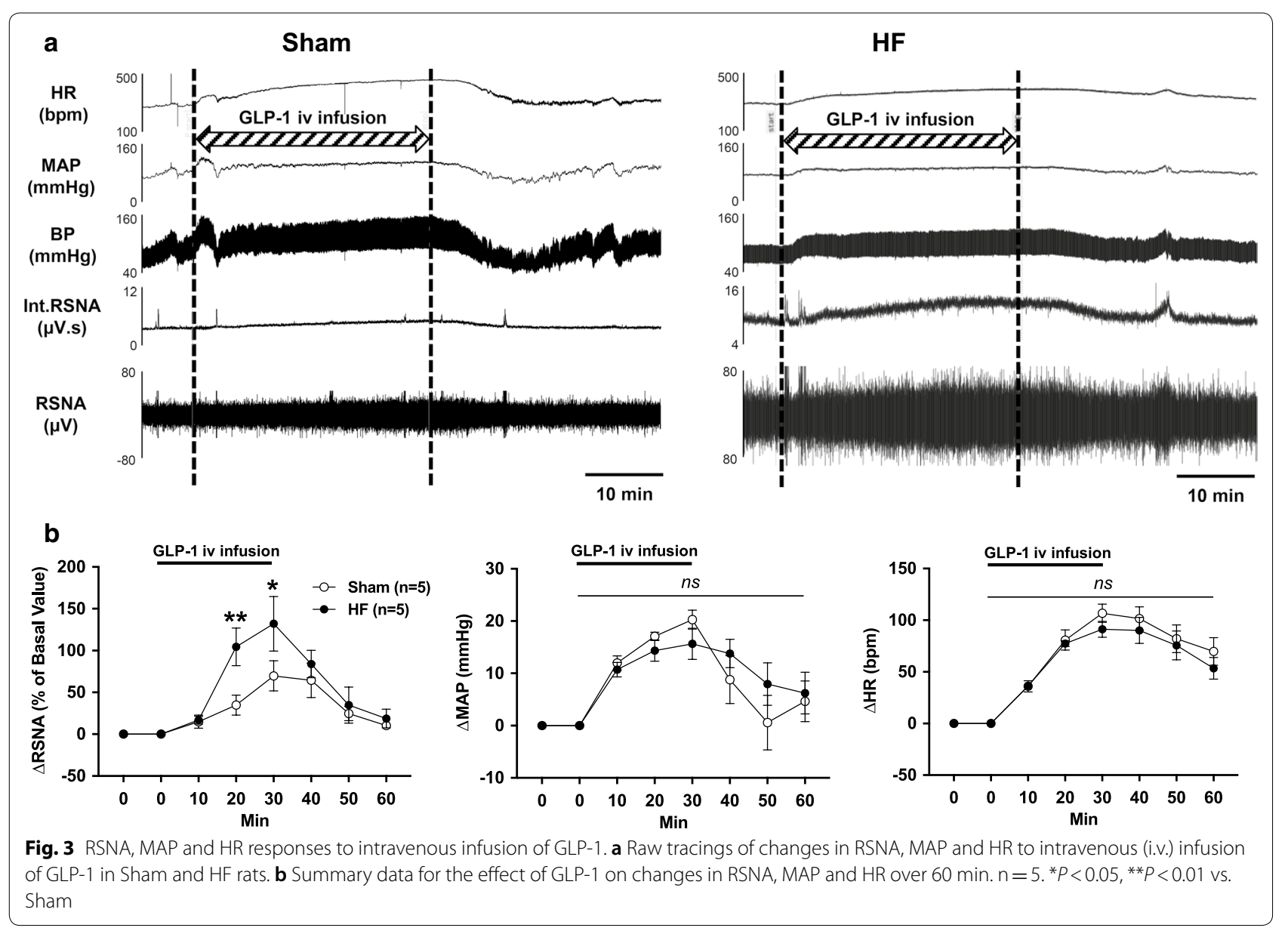

well as basal RSNA [29, 32, 33]. Intrapelvic injection of GLP-1 increased ARNA and this response was 1.5-fold greater in HF compared to Sham. One possible mechanism by which there would be enhanced response to GLP-1 in HF rats is that there is an altered expression of the GLP-1R within the renal pelvis of rats with HF. Thus, we investigated GLP-1R expressions in the renal pelvis of rats with HF by real-time qRT-PCR and western blot analysis. The mRNA levels of GLP-1Rs in the pelvis were increased in HF compared to Sham. Regarding western blot analysis, it has been reported that conventional polyclonal antibodies against the GLP-1R exhibit suboptimal sensitivity and lack of specificity $[11,13,14,52]$. In current study, we used newly developed monoclonal antibody that has previously been validated as specific for GLP-1R [24] and demonstrated that the protein levels of GLP-1Rs in the pelvis are greater in HF than Sham, suggesting that enhanced expression of GLP-1R in the pelvis leads to enhanced activation of afferent renal nerves in rats with HF. On the other hand, a previous report shows that the plasma level of active GLP-1 is not changed in rats with $\mathrm{HF}$ induced by coronary artery ligation compared to Sham [53]. Our and this finding imply that enhanced activation of afferent renal nerves by GLP-1 in HF is dependent on the expression levels of GLP-1R rather than the concentrations of GLP-1 itself in the renal pelvis.

Further, increase in RSNA by intravenous infusion of GLP-1 was 1.9-fold higher in HF than Sham, while increases in MAP and HR responses to GLP-1 were not significantly different between HF and Sham. It is well known that activation of efferent renal nerves exhibits the anti-diuretic effect by increased renin secretion, sodium reabsorption and renal vascular resistance [37, 38]. Hence, it is plausible that in HF greater increase in RSNA attenuates diuretic and natriuretic responses to GLP1. As underling mechanism of the interaction between afferent and efferent renal nerves our previous report [24] has shown that activation of afferent renal nerves leads to activation of efferent renal sympathetic nerves response to GLP-1, possibly via central neural reflex in normal rats. In this study we demonstrated that intravenous infusion of GLP-1 increased total RSNA, ARNA and efferent renal nerve activity (ERNA). It is notable 

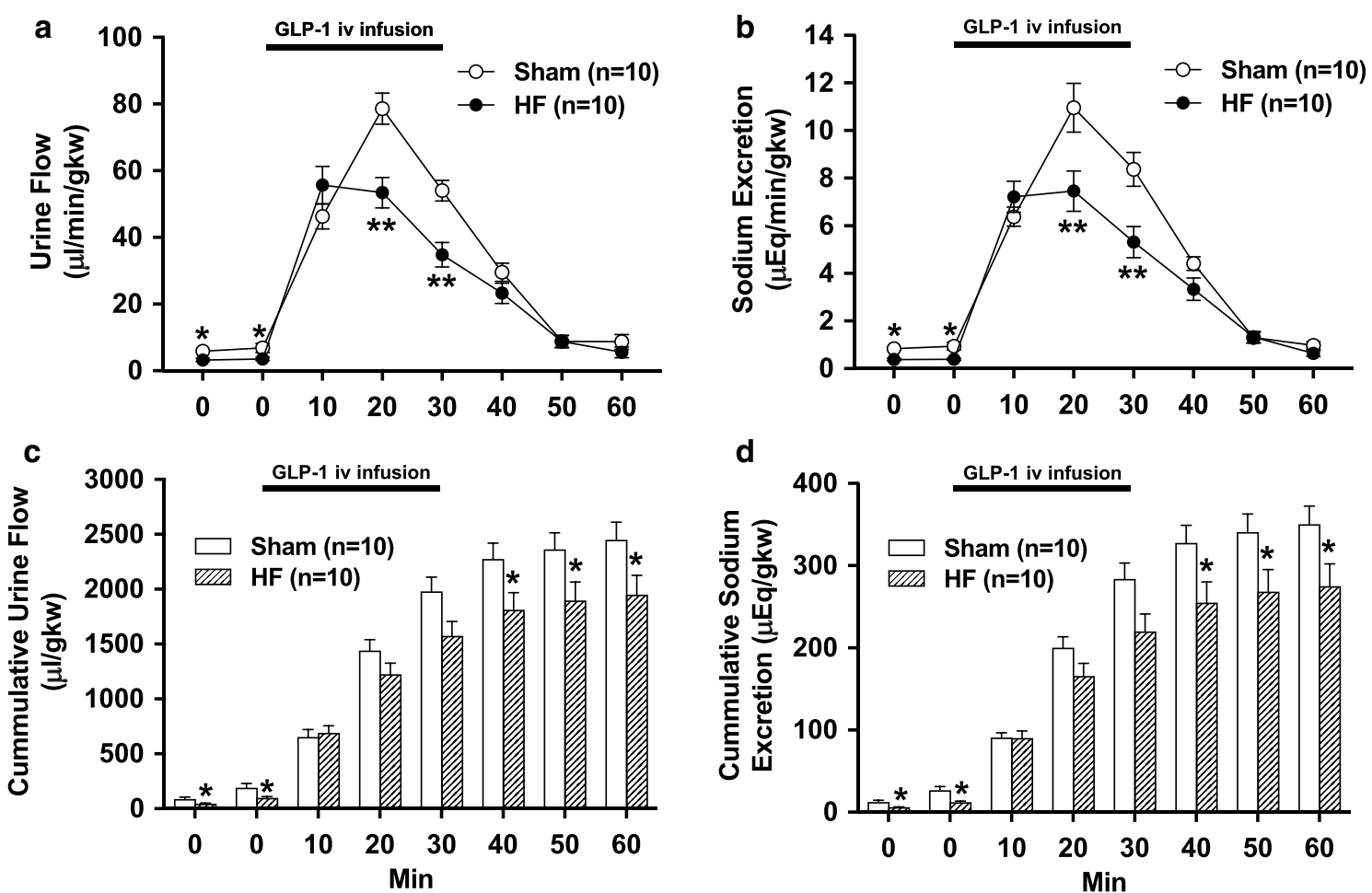

Fig. 4 Diuretic and natriuretic responses to intravenous infusion of GLP-1. Urine flow (a) and sodium excretion (b) in response to GLP-1 injection in Sham and HF rats. Cumulative values of urine flow $(\mathbf{c})$ and sodium excretion $(\mathbf{d})$ in response to GLP-1 injection in Sham and HF rats. $n=10 .{ }^{*} P<0.05$, ${ }^{* *} P<0.01$ vs. Sham

that ERNA recording obtained by cutting the distal end of the renal nerve to eliminate the afferent signal, demonstrated that response of increase in ERNA to GLP-1 is significantly diminished compared to that in total RSNA with intact renal nerves. These findings suggest that an increase in ARNA elicits the increase in ERNA to augment total RSNA. This hypothesis is further supported by a study [54] which demonstrated that electrical stimulation of afferent renal nerves activates rostral ventrolateral medulla-projecting paraventricular nucleus (PVN) neurons in the hypothalamus. These pre-autonomic neurons in the PVN are known to regulate sympathetic outflow to various peripheral organs including the kidney. Taken together, we propose that in HF enhanced activation of afferent renal nerves leads to enhanced activation of efferent renal sympathetic nerves response to GLP-1 possibly via central nervous system, thereby suppressing diuresis and natriuresis (Fig. 8).

There have been several previous studies addressing changes in diuretic and natriuretic responses to GLP-1 in disease conditions [55-57]. Some of these studies suggest that GLP-1-induced diuresis and natriuresis are attenuated in spontaneously hypertensive rats compared to normotensive rats $[56,57]$. These studies demonstrate that there is none or very little GLP-1R expression in the renal vasculature and GLP-1-induced renal artery vasodilation leading to increases in renal blood flow and glomerular filtration rate is diminished in spontaneously hypertensive rats $[56,57]$. On the other hand, another study suggests that natriuretic effect of GLP-1R agonist excendin-4 is preserved in diabetic $\mathrm{db} / \mathrm{db}$ mice [55]. Our current study is first to demonstrate that GLP-1-induced diuresis and natriuresis are attenuated in rats with HF induced by coronary artery ligation, in which the excessive activation of neural circuitry involving afferent and efferent renal nerves by GLP-1 might be implicated. These neural effects of GLP-1 possibly interact with the gut-renal axis regulating postprandial sodium and water homeostasis. The dysregulation of these neural mechanisms might contribute to renal sodium and fluid retention associated with HF.

In current study, T-RDN by itself caused significantly greater urine flow, sodium excretion and increased $\mathrm{CrCl}$ at baseline in both $\mathrm{HF}$ and Sham. These results are consistent with previous studies [30,39]. The extent of increases in diuretic and natriuretic, as well as $\mathrm{CrCl}$ responses to GLP-1 by T-RDN was greater in HF than Sham. These data suggest that in the kidneys with intact 

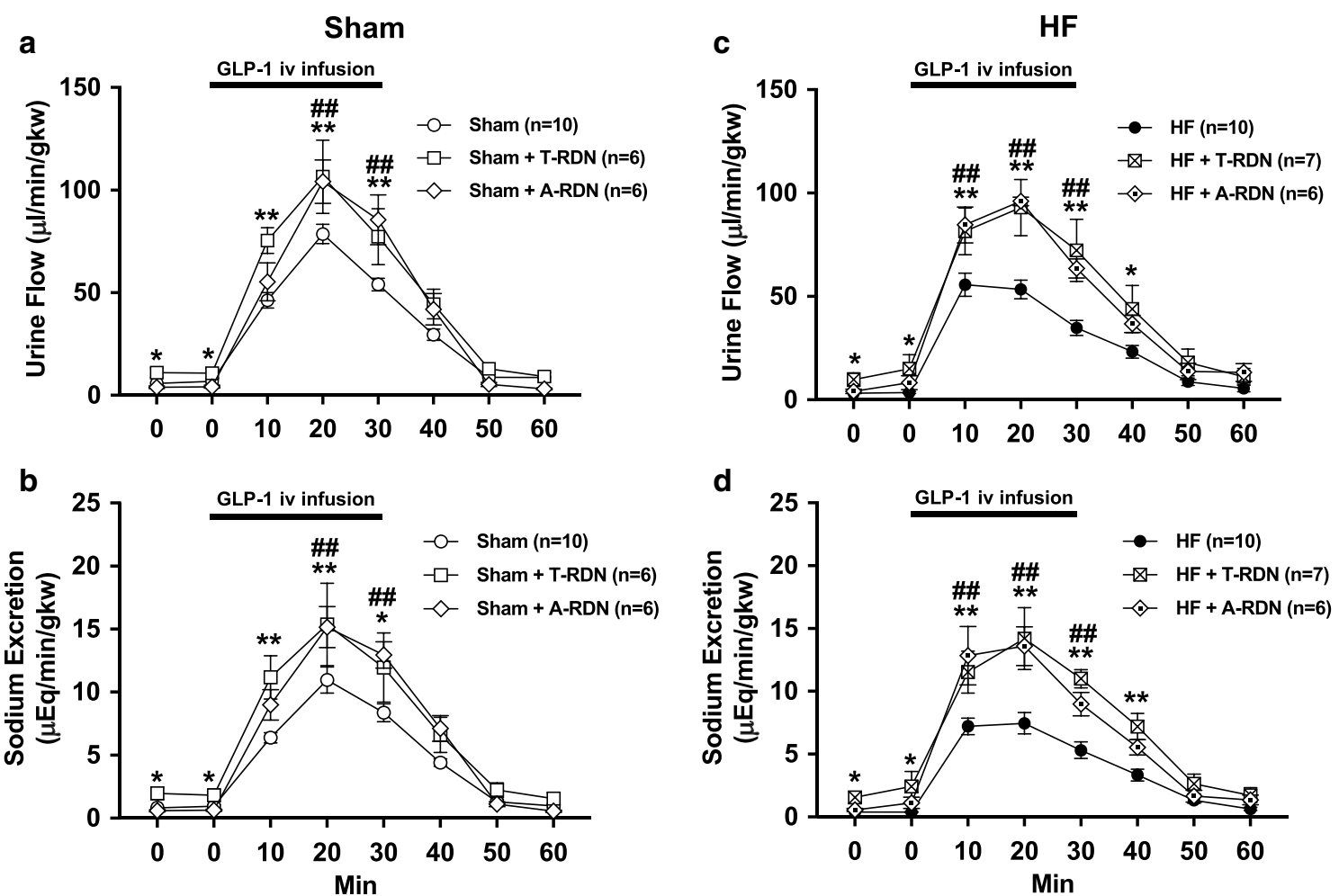

Fig. 5 Effects of T-RDN or A-RDN on diuretic and natriuretic responses to intravenous infusion of GLP-1. Urine flow (a, $\mathbf{c})$ and sodium excretion (b, d) in response to GLP-1 injection in Sham $(\mathbf{a}, \mathbf{b})$ and $\mathrm{HF}(\mathbf{c}, \mathbf{d})$ rats with or without T-RDN and A-RDN. $n=6-10 .{ }^{*} P<0.05$, ${ }^{* *} P<0.01$ between rats with and without T-RDN. ${ }^{\#} P<0.05,{ }^{\#} P<0.01$ between rats with and without A-RDN
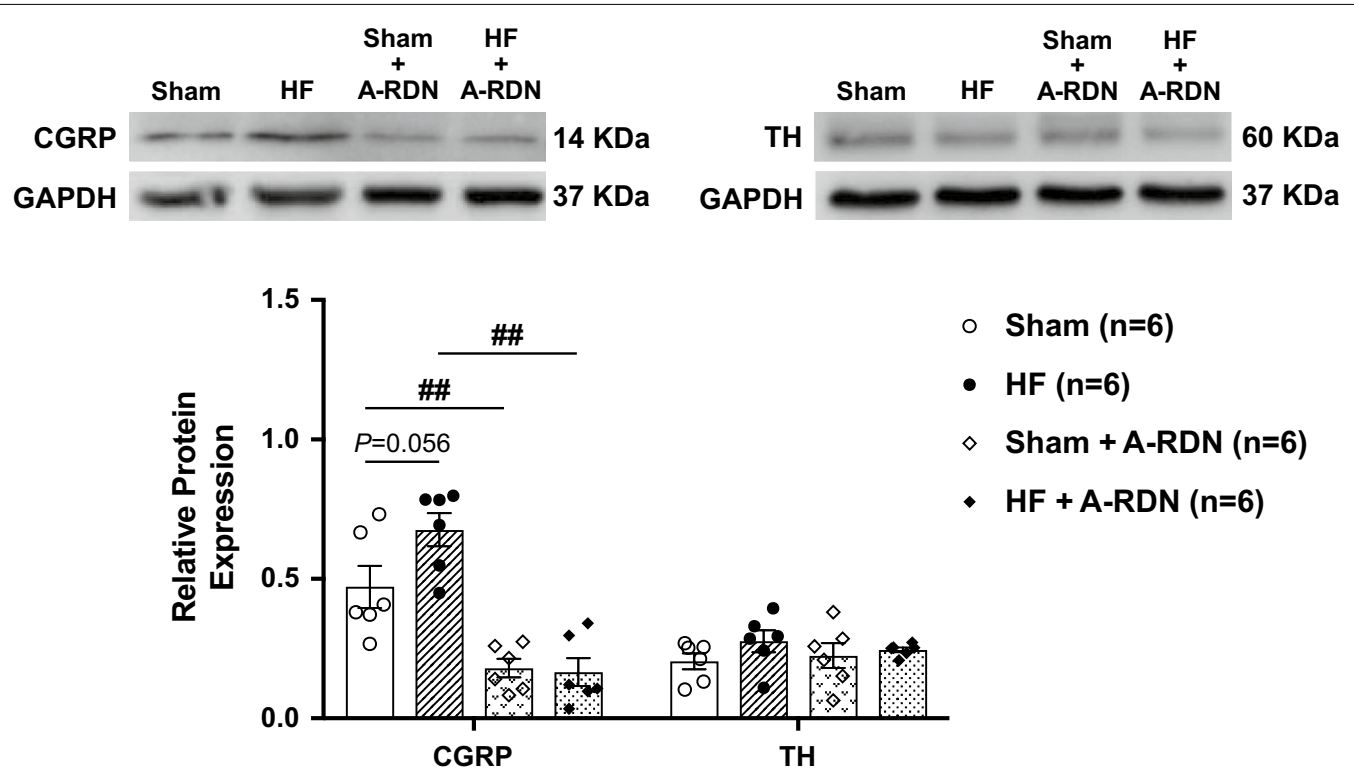

Fig. 6 Validation of A-RDN by western blot analysis. Relative CGRP and TH protein expression in the renal pelvis of Sham and HF rats with or without A-RDN. $n=6 .{ }^{\#} P<0.01$ between rats with and without A-RDN 


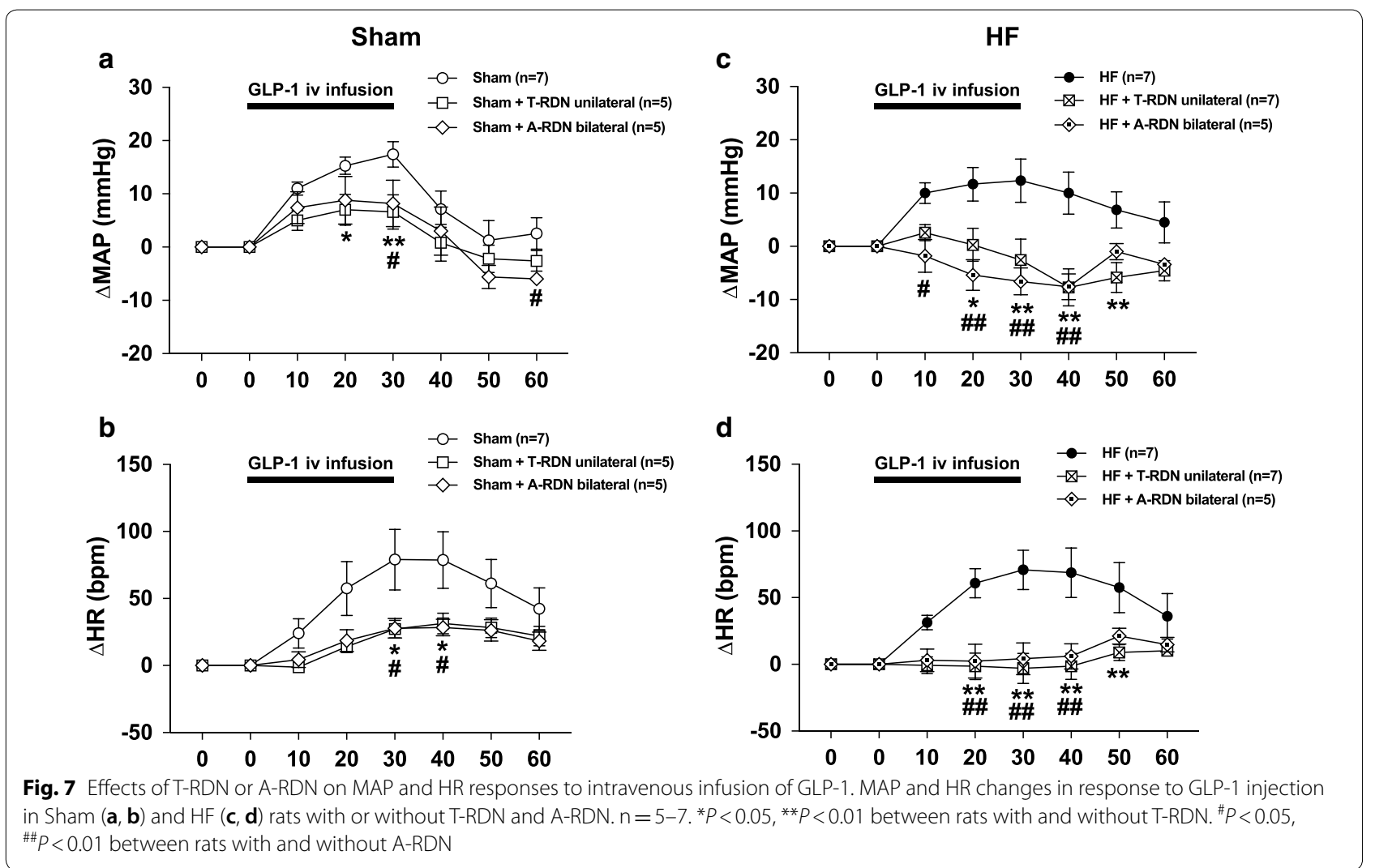

Table 2 Changes of $\mathrm{CrCl}$ during intravenous infusion of GLP-1

\begin{tabular}{|c|c|c|c|c|}
\hline & $\begin{array}{l}\text { Sham } \\
(n=5)\end{array}$ & $\begin{array}{l}\mathrm{HF} \\
(\mathrm{n}=5)\end{array}$ & Sham +T-RDN $(n=5)$ & $H F+T-R D N(n=5)$ \\
\hline \multicolumn{5}{|c|}{$\mathrm{CrCl}(\mu \mathrm{l} / \mathrm{min} / \mathrm{gkw})$} \\
\hline Baseline & $1356 \pm 109$ & $817 \pm 101^{\dagger}$ & $1893 \pm 137^{\ddagger}$ & $1858 \pm 215^{\ddagger}$ \\
\hline $20 \mathrm{~min}$ & $2225 \pm 94^{*}$ & $1725 \pm 108^{* \dagger}$ & $2978 \pm 213^{* \neq}$ & $2868 \pm 178^{* \neq}$ \\
\hline
\end{tabular}

Values are mean $\pm S E M ; n=5$ for each group of rats

$\mathrm{CrCl}$ creatinine clearance

${ }^{*} \mathrm{P}<0.05$ compared to baseline. ${ }^{\dagger} \mathrm{P}<0.05$ compared between Sham and HF. ${ }^{\ddagger} \mathrm{P}<0.05$ compared between the group with and without T-RDN

nerves, the anti-diuretic effect and inhibition of increase in $\mathrm{CrCl}$ induced by activation of efferent renal nerves response to GLP-1 are greater in HF than Sham. T-RDN inhibited GLP-1 mediated activation of efferent renal sympathetic nerve, thereby eliciting an enhanced diuresis and natriuresis, and increases in $\mathrm{CrCl}$ in HF. Furthermore, A-RDN enhanced GLP-1-induced diuresis and natriuresis as well as T-RDN, suggesting that afferent renal nerve is essential for regulating the response of increase in RSNA to GLP-1 described above.

We observed that GLP-1 increased MAP and HR in both HF and Sham rats. These results are consistent with previous reports in which GLP-1 and GLP-1R agonists cause transient increases in MAP and HR in both normotensive and hypertensive rodents [10, 13, 17, 57, 58]. Moreover, we found that increases in MAP and HR by GLP-1 were attenuated by T-RDN or A-RDN in both HF and Sham. The effects of T-RDN and those of A-RDN on MAP and HR were not significantly different between groups. These findings imply that the input from renal afferent to the central nervous system augments sympathetic outflow to the heart and the peripheral vasculatures as well as the kidney in HF and Sham. It should be noted that in current study T-RDN was performed unilaterally while A-RDN was performed bilaterally. Since unilateral T-RDN and 


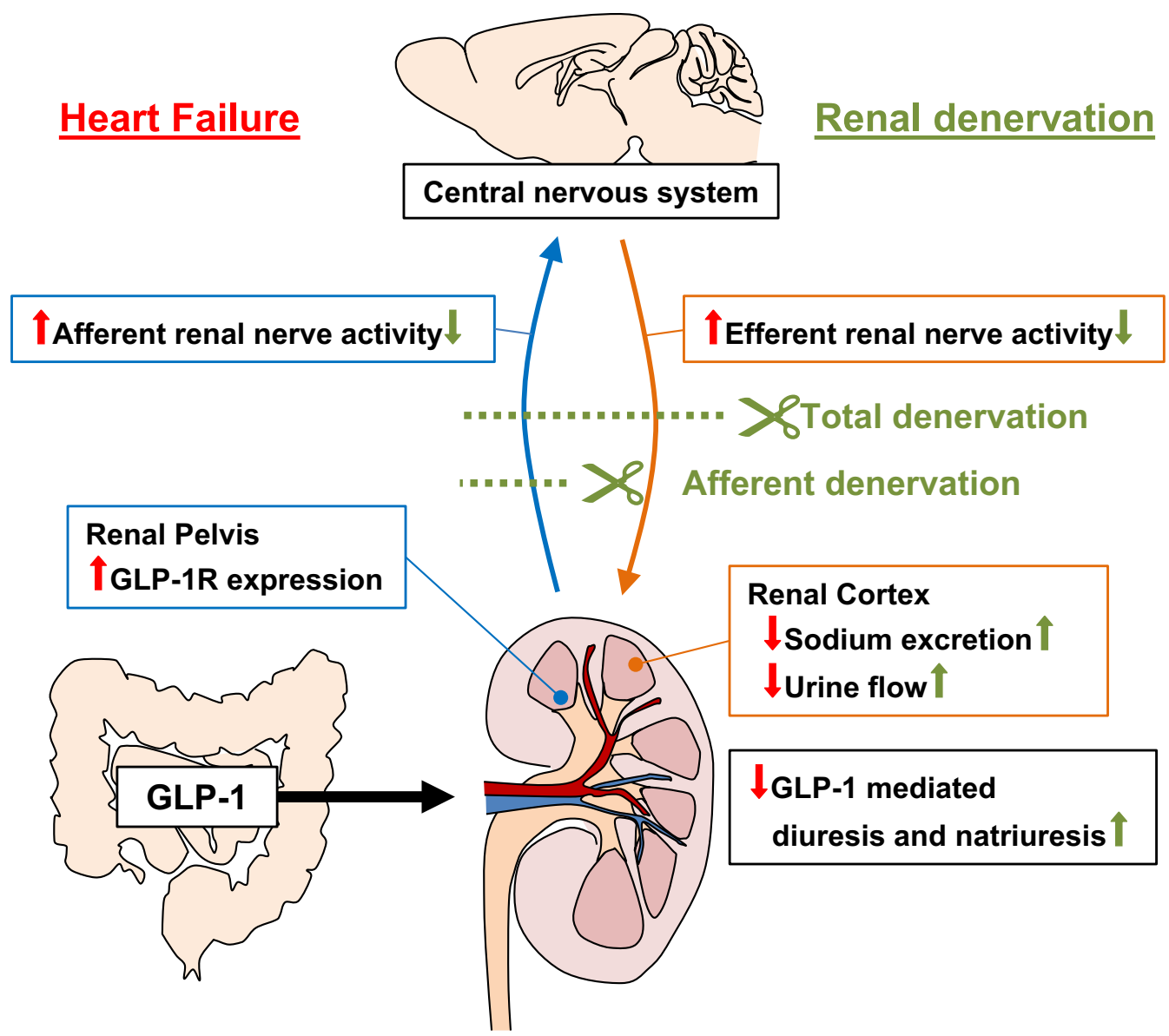

Fig. 8 Proposed model for neural mechanisms in regulating GLP-1 mediated diuresis and natriuresis in HF. GLP-1 activates afferent renal nerve via GLP-1R expressed in the renal pelvis to increase efferent renal nerve activity that regulate diuresis and natriuresis in an inhibitory manner. In $\mathrm{HF}$ condition, there is an excessive activation of afferent renal nerve due to an overexpression of GLP-1R in the renal pelvis resulting in an excessive activation of efferent renal nerve thereby suppressing diuresis and natriuresis. Either A-RDN or T-RDN inhibits the activation of neural circuitry utilizing the renal nerves to restore GLP-1 mediated diuresis and natriuresis

bilateral A-RDN had comparable effects on GLP-1 mediated hemodynamic changes, it is possible that unilateral interruption of renal afferent input (limited input) to the central nervous system is sufficient to reduce sympathetic outflow affecting GLP-1 mediated hemodynamic changes. These findings are consistent with a previous study reporting that unilateral T-RDN affects global autonomic balance to restore baroreflex dysfunction associated with HF in rabbits [59]. To further assess the additive effects of bilateral versus unilateral T-RDN on GLP-1 mediated hemodynamic changes remains to be examined.

It has been reported that GLP-1 can improve energy efficiency by increasing glucose assimilation in the heart, which promote cardiac performance $[60,61]$. In current study we have demonstrated that GLP-1 increased BP and $H R$ accompanied with diuresis and natriuresis. One possible interpretation could be that GLP-1 promotes cardiac performance to increase BP and HR inducing pressure natriuresis. On the other hand, RDN enhances diuresis despite decreasing BP response to GLP-1, suggesting that GLP-1 mediated diuresis and natriuresis are mainly regulated by renal sympathetic nerve activity rather than pressure natriuresis affected by cardiac performance.

Effect of GLP-1 on HF has been a subject of active debate [6-9]. In animal models of HF, GLP-1R agonists increase myocardial glucose uptake [62], stroke volume and LVEF, accompanied by decreasing LVEDP and systemic vascular resistance [63]. Additionally, diuretic and natriuretic effects of GLP-1 seem to be beneficial for HF. However, these positive benefits in animal studies have apparently not been translated into likely beneficial clinical outcomes. Cardiovascular outcome studies of GLP-1R agonists do not affect the rate of heart failure hospitalization, while decreasing the rate of myocardial infarction 
and stroke [3-5]. On the other hand, there are some clinical studies suggesting the association between GLP-1 related medicines and the increased risk of HF hospitalization [64-67]. In diabetic patients with advanced HF and reduced $L V E F<40 \%$, GLP-1R agonist had a tendency to increase the risk of rehospitalization for HF [66]. Other studies showed that dipeptidyl peptidase 4 inhibitors, GLP-1 enhancers, significantly increased the risk of hospitalization for HF $[64,65]$. From the point of view of clinical relevance, pathophysiological responses to GLP-1 demonstrated in current study including acute increases in RSNA, MAP and HR and decreases in diuresis and natriuresis, all features that are likely to be unfavorable and might contribute to a greater risk for HF.

A previous study has shown that the combination of GLP-1R agonist and angiotensin receptor blocker (ARB) increases natriuresis compared to GLP-1R agonist alone in Otsuka Long-Evans Tokushima Fatty rats, a model of obese type 2 diabetes [68]. Further, a clinical study has demonstrated that the combination of GLP-1R agonist and sodium-glucose cotransporter 2 (SGLT2) inhibitors significantly reduces the risk of all cause-mortality and improves renal function, compared to GLP-1R agonist alone in type 2 diabetic patients [69]. ARBs and SGLT2 inhibitors could exert sympathoinhibitory effects in HF [70-73] and thus restore the diuretic and natriuretic effects of GLP-1. These results are similar to the effects of RDN demonstrated in current study, providing additional insight into safety and benefit of combination treatment with GLP-1 related medicines for diabetic HF patients.

\section{Conclusions}

We have shown that GLP-1R expression in renal pelvis densely innervated by afferent renal nerves was enhanced in HF. The excessive activation of neural circuitry of afferent and efferent renal nerves in HF suppressed diuretic and natriuretic responses to GLP-1. T-RDN or A-RDN restored diuretic and natriuretic effects of GLP-1 (Fig. 8) and has potential therapeutic implication for use of the new catheter based renal denervation technique in diabetic HF patients [74-76].

\footnotetext{
Abbreviations

GLP-1: Glucagon-like peptide-1; GLP-1R: GLP-1 receptor; HF: Heart failure; LVEDD: Left ventricular end-diastolic dimension; LVESD: Left ventricular endsystolic dimension; FS: Fractional shortening; EF: Ejection fraction; LVEDV: Left ventricular end-diastolic volume; LVESV: Left ventricular end-systolic volume; SV: Stroke volume; CO: Cardiac output; LVEDP: Left ventricular end-diastolic pressure; LVESP: Left ventricular end-systolic pressure; +dP/dt: Maximal slope of systolic pressure increment; -dP/dt: Maximal slope of diastolic pressure decrement; LV: Left ventricle; ARNA: Afferent renal nerve activity; MAP: Mean arterial pressure; HR: Heart rate; qRT-PCR: Quantitative reverse-transcription polymerase chain reaction; TBST: Tris-buffered saline with tween 20; RSNA: Renal sympathetic nerve activity; T-RDN: Total renal denervation; A-RDN: Afferent renal denervation; CGRP: Calcitonin gene-related peptide; TH: Tyrosine hydroxylase; $\mathrm{CrCl}$ : Creatinine clearance; ERNA: Efferent renal nerve activity;
}

PVN: Paraventricular nucleus; ARB: Angiotensin receptor blocker; SGLT2: Sodium-glucose cotransporter 2 .

\section{Acknowledgements}

The surgical assistance of Kaye L. Talbitzer and the assistance of Bryan T. Hackfort for doing the Echocardiograms are greatly appreciated.

\section{Authors' contributions}

KK and KPP conceived and designed research. KK, SSN, HZ, XL and NMS performed experiments and analyzed data. KK, SSN, HZ, XL, NMS and KPP interpreted results of experiments. KK, SSN and NMS prepared figures. KK and KPP drafted manuscript. All authors read and approved the final manuscript.

\section{Funding}

This work was supported by National Institutes of Health Grants R01-DK-114663, P01-HL-62222 and endowed McIntyre Professorship to K.P. Patel, and Japan Heart Foundation/Bayer Yakuhin Research Grant Abroad (to K. Katsurada).

\section{Availability of data and materials}

All data generated or analyzed during this study are included in this published article.

\section{Ethics approval and consent to participate}

All procedures used for this study were approved by University of Nebraska Medical Center Institutional Animal Care and Use Committee (IACUC, approval reference number: 14-036-07-FC) and conducted according to the National Institutes of Health guiding principles for the research involving animals.

\section{Consent for publications}

Not applicable.

\section{Competing interests}

The authors declare that they have no competing interests.

\section{Author details}

${ }^{1}$ Department of Cellular and Integrative Physiology, University of Nebraska Medical Center, 985850 Nebraska Medical Center, Omaha, NE 68198-5850, USA. ${ }^{2}$ Division of Basic Biomedical Sciences, Sanford School of Medicine of the University of South Dakota, Vermillion, SD, USA.

Received: 11 February 2020 Accepted: 25 April 2020

Published online: 08 May 2020

References

1. Holst JJ. The physiology of glucagon-like peptide 1. Physiol Rev. 2007;87(4):1409-39.

2. Katsurada K, Maejima Y, Nakata M, Kodaira M, Suyama S, Iwasaki Y, et al. Endogenous GLP-1 acts on paraventricular nucleus to suppress feeding: projection from nucleus tractus solitarius and activation of corticotropinreleasing hormone, nesfatin- 1 and oxytocin neurons. Biochem Biophys Res Commun. 2014;451(2):276-81.

3. Marso SP, Daniels GH, Brown-Frandsen K, Kristensen P, Mann JF, Nauck MA, et al. Liraglutide and cardiovascular outcomes in type 2 diabetes. N Engl J Med. 2016:375(4):311-22.

4. Marso SP, Bain SC, Consoli A, Eliaschewitz FG, Jodar E, Leiter LA, et al. Semaglutide and cardiovascular outcomes in patients with type 2 diabetes. N Engl J Med. 2016;375(19):1834-44.

5. Mann JFE, Fonseca V, Mosenzon O, Raz I, Goldman B, Idorn T, et al. Effects of liraglutide versus placebo on cardiovascular events in patients with type 2 diabetes mellitus and chronic kidney disease. Circulation. 2018:138(25):2908-18.

6. Packer M. Is the way to someone's heart through their stomach? The cardiorenal paradox of incretin-based hypoglycemic drugs in heart failure. Circ Heart Fail. 2017;10(10):e004551.

7. Scheen AJ. GLP-1 receptor agonists and heart failure in diabetes. Diabetes Metab. 2017:43(Suppl 1):2S13-9. 
8. Packer M. Will long-acting glucagon-like peptide-1 analogues recapitulate our agonizing experience with cyclic AMP-dependent positive inotropic agents in heart failure? Eur J Heart Fail. 2018;20(4):627-9.

9. Tanaka A, Node K. Clinical application of glucagon-like peptide-1 receptor agonists in cardiovascular disease: lessons from recent clinical cardiovascular outcomes trials. Cardiovasc Diabetol. 2018;17(1):85.

10. Ussher JR, Drucker DJ. Cardiovascular actions of incretin-based therapies. Circ Res. 2014;114(11):1788-803.

11. Pyke C, Heller RS, Kirk RK, Orskov C, Reedtz-Runge S, Kaastrup P, et al. GLP-1 receptor localization in monkey and human tissue: novel distribution revealed with extensively validated monoclonal antibody. Endocrinology. 2014;155(4):1280-90.

12. Jensen EP, Poulsen SS, Kissow H, Holstein-Rathlou NH, Deacon CF, Jensen $\mathrm{BL}$, et al. Activation of GLP-1 receptors on vascular smooth muscle cells reduces the autoregulatory response in afferent arterioles and increases renal blood flow. Am J Physiol Renal Physiol. 2015;308(8):F867-77.

13. Drucker DJ. The cardiovascular biology of glucagon-like peptide-1. Cell Metab. 2016;24(1):15-30.

14. Muskiet MHA, Tonneijck L, Smits MM, van Baar MJB, Kramer MHH, Hoorn EJ, et al. GLP-1 and the kidney: from physiology to pharmacology and outcomes in diabetes. Nat Rev Nephrol. 2017;13(10):605-28.

15. Baggio LL, Yusta B, Mulvihill EE, Cao X, Streutker CJ, Butany J, et al. GLP-1 receptor expression within the human heart. Endocrinology. 2018;159(4):1570-84.

16. Asmar A, Cramon PK, Simonsen L, Asmar M, Sorensen CM, Madsbad S, et al. Extracellular fluid volume expansion uncovers a natriuretic action of GLP-1: a functional GLP-1-renal axis in man. J Clin Endocrinol Metab. 2019;104(7):2509-19.

17. Kim M, Platt MJ, Shibasaki T, Quaggin SE, Backx PH, Seino S, et al. GLP-1 receptor activation and Epac2 link atrial natriuretic peptide secretion to control of blood pressure. Nat Med. 2013;19(5):567-75.

18. Kastin AJ, Akerstrom V, Pan W. Interactions of glucagon-like peptide-1 (GLP-1) with the blood-brain barrier. J Mol Neurosci. 2002;18(1-2):7-14.

19. Hunter K, Holscher C. Drugs developed to treat diabetes, liraglutide and lixisenatide, cross the blood brain barrier and enhance neurogenesis. BMC Neurosci. 2012;13:33.

20. Secher A, Jelsing J, Baquero AF, Hecksher-Sorensen J, Cowley MA, Dalboge LS, et al. The arcuate nucleus mediates GLP-1 receptor agonist liraglutide-dependent weight loss. J Clin Investig. 2014;124(10):4473-88.

21. Kakei M, Yada T, Nakagawa A, Nakabayashi H. Glucagon-like peptide-1 evokes action potentials and increases cytosolic $\mathrm{Ca}^{2+}$ in rat nodose ganglion neurons. Auton Neurosci. 2002;102(1-2):39-44.

22. Katsurada K, Yada T. Neural effects of gut- and brain-derived glucagonlike peptide-1 and its receptor agonist. J Diabetes Investig. 2016;7(Suppl 1):64-9.

23. Iwasaki Y, Goswami C, Yada T. Glucagon-like peptide-1 and insulin synergistically activate vagal afferent neurons. Neuropeptides. 2017;65:77-82.

24. Katsurada K, Nandi SS, Sharma NM, Zheng H, Liu X, Patel KP. Does glucagon-like peptide-1 induce diuresis and natriuresis by modulating afferent renal nerve activity? Am J Physiol Renal Physiol. 2019;317(4):F1010-21.

25. Foss JD, Wainford RD, Engeland WC, Fink GD, Osborn JW. A novel method of selective ablation of afferent renal nerves by periaxonal application of capsaicin. Am J Physiol Regul Integr Comp Physiol. 2015;308(2):R112-22.

26. Zheng H, Katsurada K, Liu X, Knuepfer MM, Patel KP. Specific afferent renal denervation prevents reduction in neuronal nitric oxide synthase within the paraventricular nucleus in rats with chronic heart failure. Hypertension. 2018;72(3):667-75.

27. Patel KP, Zhang PL, Krukoff TL. Alterations in brain hexokinase activity associated with heart failure in rats. Am J Physiol. 1993;265(4 Pt 2):R923-8.

28. Patel KP, Zhang PL, Carmines PK. Neural influences on renal responses to acute volume expansion in rats with heart failure. Am J Physiol. 1996:271 (4 Pt 2):H1441-8.

29. Zhang K, Li YF, Patel KP. Reduced endogenous GABA-mediated inhibition in the PVN on renal nerve discharge in rats with heart failure. Am J Physiol Regul Integr Comp Physiol. 2002;282(4):R1006-15.

30. Zheng H, Li YF, Zucker IH, Patel KP. Exercise training improves renal excretory responses to acute volume expansion in rats with heart failure. Am J Physiol Renal Physiol. 2006;291(6):F1148-56.

31. Li YF, Mayhan WG, Patel KP. Role of the paraventricular nucleus in renal excretory responses to acute volume expansion: role of nitric oxide. Am J Physiol Heart Circ Physiol. 2003;285(4):H1738-46.
32. Sharma NM, Cunningham CJ, Zheng H, Liu X, Patel KP. Hypoxia-inducible factor-1alpha mediates increased sympathoexcitation via glutamatergic $\mathrm{N}$-methyl-D-aspartate receptors in the paraventricular nucleus of rats with chronic heart failure. Circ Heart Fail. 2016;9(11):e003423.

33. Sharma NM, Liu X, Llewellyn TL, Katsurada K, Patel KP. Exercise training augments neuronal nitric oxide synthase dimerization in the paraventricular nucleus of rats with chronic heart failure. Nitric Oxide. 2019;87:73-82

34. Banek CT, Knuepfer MM, Foss JD, Fiege JK, Asirvatham-Jeyaraj N, Van Helden D, et al. Resting afferent renal nerve discharge and renal inflammation: elucidating the role of afferent and efferent renal nerves in deoxycorticosterone acetate salt hypertension. Hypertension. 2016:68(6):1415-23.

35. Goodwill VS, Terrill C, Hopewood I, Loewy AD, Knuepfer MM. CNS sites activated by renal pelvic epithelial sodium channels ( $\mathrm{ENaCs}$ ) in response to hypertonic saline in awake rats. Auton Neurosci. 2017;204:35-47.

36. Patel KP, Kline RL. Influence of renal nerves on noradrenergic responses to changes in arterial pressure. Am J Physiol. 1984;247(4 Pt 2):R615-20.

37. Johns EJ, Kopp UC, DiBona GF. Neural control of renal function. Compr Physiol. 2011;1(2):731-67.

38. Osborn JW, Foss JD. Renal nerves and long-term control of arterial pressure. Compr Physiol. 2017;7(2):263-320.

39. Zheng H, Liu X, Rao US, Patel KP. Increased renal ENaC subunits and sodium retention in rats with chronic heart failure. Am J Physiol Renal Physiol. 2011;300(3):F641-9.

40. Zheng H, Liu X, Katsurada K, Patel KP. Renal denervation improves sodium excretion in rats with chronic heart failure: effects on expression of renal ENaC and AQP2. Am J Physiol Heart Circ Physiol. 2019;317(5):H958-68.

41. Balakumar P, Singh AP, Singh M. Rodent models of heart failure. J Pharmacol Toxicol Methods. 2007;56(1):1-10.

42. Patten RD, Hall-Porter MR. Small animal models of heart failure: development of novel therapies, past and present. Circ Heart Fail. 2009;2(2):138-44.

43. Houser SR, Margulies KB, Murphy AM, Spinale FG, Francis GS, Prabhu SD, et al. Animal models of heart failure: a scientific statement from the American Heart Association. Circ Res. 2012;111(1):131-50.

44. Zheng H, Liu X, Sharma NM, Patel KP. Renal denervation improves cardiac function in rats with chronic heart failure: effects on expression of betaadrenoceptors. Am J Physiol Heart Circ Physiol. 2016;311(2):H337-46.

45. Zheng C, Lin JF, Lin ZH, Lin WQ, Thapa S, Lin YZ, et al. Sodium houttuyfonate alleviates post-infarct remodeling in rats via AMP-activated protein kinase pathway. Front Pharmacol. 2018;9:1092

46. Yang C, Liu J, Liu K, Du B, Shi K, Ding M, et al. Ghrelin suppresses cardiac fibrosis of post-myocardial infarction heart failure rats by adjusting the activin A-follistatin imbalance. Peptides. 2018;99:27-35.

47. Qiu Q, Cao J, Wang Y, Zhang Y, Wei Y, Hao X, et al. Time course of the effects of Buxin Yishen decoction in promoting heart function and inhibiting the progression of renal fibrosis in myocardial infarction caused type 2 cardiorenal syndrome rats. Front Pharmacol. 2019;10:1267.

48. He J, Lu Y, Song X, Gong X, Li Y. Inhibition of microRNA-146a attenuated heart failure in myocardial infarction rats. Biosci Rep. 2019;39:BSR20191732.

49. Wen Y, Li XY, Li ZY, Wang ML, Chen PP, Liu Y, et al. Intra-myocardial delivery of a novel thermosensitive hydrogel inhibits post-infarct heart failure after degradation in rat. J Cardiovasc Transl Res. 2020. https://doi. org/10.1007/s12265-019-09941-X.

50. Gao H, Huang $X$, Tong $Y$, Jiang $X$. Urolithin B improves cardiac function and reduces susceptibility to ventricular arrhythmias in rats after myocardial infarction. Eur J Pharmacol. 2020;871:172936.

51. Zhang K, Wiedemann S, Dschietzig M, Cremers MM, Augstein A, Poitz DM et al. The infarction zone rather than the noninfarcted remodeling zone overexpresses angiotensin II receptor type 1 and is the main source of ventricular atrial natriuretic peptide. Cardiovasc Pathol. 2020;44:107160.

52. Pyke C, Knudsen LB. The glucagon-like peptide-1 receptor-or not? Endocrinology. 2013;154(1):4-8.

53. Yin M, Sillje HH, Meissner M, van Gilst WH, de Boer RA. Early and late effects of the DPP-4 inhibitor vildagliptin in a rat model of post-myocardial infarction heart failure. Cardiovasc Diabetol. 2011;10:85.

54. Xu B, Zheng H, Liu X, Patel KP. Activation of afferent renal nerves modulates RVLM-projecting PVN neurons. Am J Physiol Heart Circ Physiol. 2015;308(9):H1103-11. 
55. Rieg T, Gerasimova M, Murray F, Masuda T, Tang T, Rose M, et al. Natriuretic effect by exendin-4, but not the DPP- 4 inhibitor alogliptin, is mediated via the GLP-1 receptor and preserved in obese type 2 diabetic mice. Am J Physiol Renal Physiol. 2012;303(7):F963-71.

56. Savignano FA, Crajoinas RO, Pacheco BPM, Campos LCG, Shimizu MHM, Seguro AC, et al. Attenuated diuresis and natriuresis in response to glucagon-like peptide-1 in hypertensive rats are associated with lower expression of the glucagon-like peptide-1 receptor in the renal vasculature. Eur J Pharmacol. 2017;811:38-47.

57. Ronn J, Jensen EP, Wewer Albrechtsen NJ, Holst JJ, Sorensen CM. Glucagon-like peptide-1 acutely affects renal blood flow and urinary flow rate in spontaneously hypertensive rats despite significantly reduced renal expression of GLP-1 receptors. Physiol Rep. 2017;5(23):e13503.

58. Yamamoto H, Lee CE, Marcus JN, Williams TD, Overton JM, Lopez ME, et al. Glucagon-like peptide-1 receptor stimulation increases blood pressure and heart rate and activates autonomic regulatory neurons. J Clin Investig. 2002;110(1):43-52.

59. Schiller AM, Haack KK, Pellegrino PR, Curry PL, Zucker IH. Unilateral renal denervation improves autonomic balance in conscious rabbits with chronic heart failure. Am J Physiol Regul Integr Comp Physiol. 2013;305(8):R886-92.

60. Giannocco G, Oliveira KC, Crajoinas RO, Venturini G, Salles TA, FonsecaAlaniz MH, et al. Dipeptidyl peptidase IV inhibition upregulates GLUT4 translocation and expression in heart and skeletal muscle of spontaneously hypertensive rats. Eur J Pharmacol. 2013;698(1-3):74-86.

61. Ramirez E, Picatoste B, Gonzalez-Bris A, Oteo M, Cruz F, Caro-Vadillo A, et al. Sitagliptin improved glucose assimilation in detriment of fatty-acid utilization in experimental type-II diabetes: role of GLP-1 isoforms in Glut4 receptor trafficking. Cardiovasc Diabetol. 2018;17(1):12.

62. Bhashyam S, Fields AV, Patterson B, Testani JM, Chen L, Shen YT, et al. Glucagon-like peptide-1 increases myocardial glucose uptake via p38alpha MAP kinase-mediated, nitric oxide-dependent mechanisms in conscious dogs with dilated cardiomyopathy. Circ Heart Fail. 2010;3(4):512-21.

63. Nikolaidis LA, Elahi D, Hentosz T, Doverspike A, Huerbin R, Zourelias L, et al. Recombinant glucagon-like peptide- 1 increases myocardial glucose uptake and improves left ventricular performance in conscious dogs with pacing-induced dilated cardiomyopathy. Circulation. 2004;110(8):955-61.

64. Scirica BM, Braunwald E, Raz I, Cavender MA, Morrow DA, Jarolim P, et al. Heart failure, saxagliptin, and diabetes mellitus: observations from the SAVOR-TIMI 53 randomized trial. Circulation. 2014;130(18):1579-88.

65. Zannad F, Cannon CP, Cushman WC, Bakris GL, Menon V, Perez AT, et al. Heart failure and mortality outcomes in patients with type 2 diabetes taking alogliptin versus placebo in EXAMINE: a multicentre, randomised, double-blind trial. Lancet. 2015;385(9982):2067-76.
66. Margulies KB, Hernandez AF, Redfield MM, Givertz MM, Oliveira GH, Cole $R$, et al. Effects of liraglutide on clinical stability among patients with advanced heart failure and reduced ejection fraction: a randomized clinical trial. JAMA. 2016;316(5):500-8.

67. Nassif M, Kosiborod M. Effect of glucose-lowering therapies on heart failure. Nat Rev Cardiol. 2018;15(5):282-91.

68. Rodriguez R, Moreno M, Lee AY, Godoy-Lugo JA, Nakano D, Nishiyama A, et al. Simultaneous GLP-1 receptor activation and angiotensin receptor blockade increase natriuresis independent of altered arterial pressure in obese OLETF rats. Hypertens Res. 2018:41 (10):798-808.

69. Clegg LE, Penland RC, Bachina S, Boulton DW, Thuresson M, Heerspink HJL, et al. Effects of exenatide and open-label SGLT2 inhibitor treatment, given in parallel or sequentially, on mortality and cardiovascular and renal outcomes in type 2 diabetes: insights from the EXSCEL trial. Cardiovasc Diabetol. 2019;18(1):138.

70. Li YF, Wang W, Mayhan WG, Patel KP. Angiotensin-mediated increase in renal sympathetic nerve discharge within the PVN: role of nitric oxide. Am J Physiol Regul Integr Comp Physiol. 2006;290(4):R1035-43.

71. Zheng H, Sharma NM, Liu X, Patel KP. Exercise training normalizes enhanced sympathetic activation from the paraventricular nucleus in chronic heart failure: role of angiotensin II. Am J Physiol Regul Integr Comp Physiol. 2012;303(4):R387-94.

72. Kishi T, Hirooka Y, Sunagawa K. Telmisartan reduces mortality and left ventricular hypertrophy with sympathoinhibition in rats with hypertension and heart failure. Am J Hypertens. 2014;27(2):260-7.

73. Sano M. A new class of drugs for heart failure: SGLT2 inhibitors reduce sympathetic overactivity. J Cardiol. 2018:71(5):471-6.

74. Sobotka PA, Krum H, Bohm M, Francis DP, Schlaich MP. The role of renal denervation in the treatment of heart failure. Curr Cardiol Rep. 2012;14(3):285-92.

75. Davies JE, Manisty CH, Petraco R, Barron AJ, Unsworth B, Mayet J, et al. First-in-man safety evaluation of renal denervation for chronic systolic heart failure: primary outcome from REACH-Pilot study. Int J Cardiol. 2013;162(3):189-92.

76. Hopper I, Gronda E, Hoppe UC, Rundqvist B, Marwick TH, Shetty S, et al. Sympathetic response and outcomes following renal denervation in patients with chronic heart failure: 12-month outcomes from the symplicity HF feasibility study. J Card Fail. 2017;23(9):702-7.

\section{Publisher's Note}

Springer Nature remains neutral with regard to jurisdictional claims in published maps and institutional affiliations.
Ready to submit your research? Choose BMC and benefit from:

- fast, convenient online submission

- thorough peer review by experienced researchers in your field

- rapid publication on acceptance

- support for research data, including large and complex data types

- gold Open Access which fosters wider collaboration and increased citations

- maximum visibility for your research: over $100 \mathrm{M}$ website views per year

At BMC, research is always in progress.

Learn more biomedcentral.com/submissions 